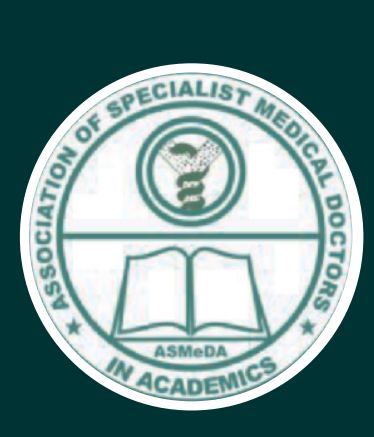

ISSN:Print: 2811-1672

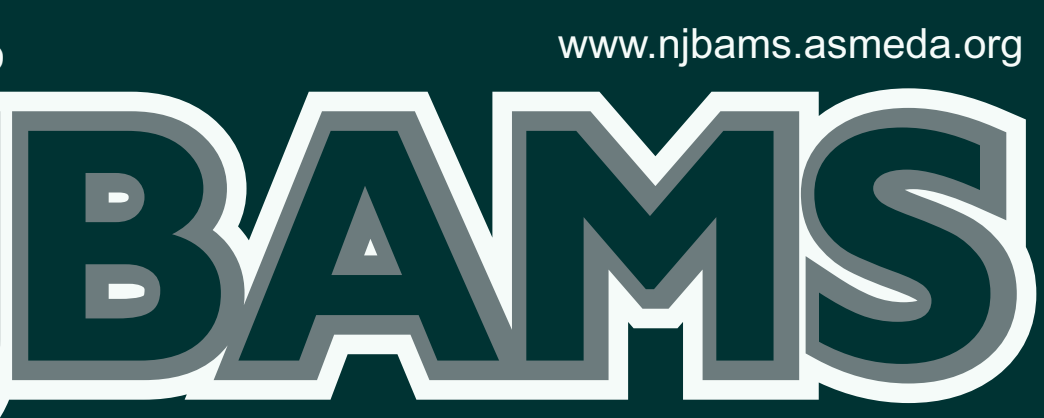

Nigerian Journal of Basic and Applied Medical Sciences

An official publication of the National

ASSOCIATION OF SPECIALIST MEDICAL DOCTORS IN

ACADEMICS (ASMeDA aka MEDSABAMS) 


\title{
Castor oil Induces Morphological Changes in Endometrium and Biochemical Parameters in Pregnant Wistar Rats
}

\author{
Kadir E.R. ${ }^{1}$, Ibrahim A. ${ }^{2}$, Imam A., Onigbolabi O.G. ${ }^{1}$, Imam A.A. ${ }^{1}$, Ajao M.S. ${ }^{1}$
}

${ }^{1}$ Department of Anatomy, College of Health Sciences, University of Ilorin, Ilorin, Nigeria.

${ }^{2}$ University of Cape Town, South Africa.

\section{ABSTRACT}

Background: Misoprostol is a synthetic prostaglandin E1 analogue, used for the management of miscarriages and labour. Castor oil is a natural plant extract that has been reported to have some abortifacient Properties

Objectives: This study investigated the labour induction and abortifacient properties of castor oil, as well as possible effects on the electrolytes and hormones that regulate pregnancy, as well as to compare these effects with a standard labour inducing drug misoprostol, in Wistar rats.

Methods: The study was conducted out in 2 phases. The pregnant rats were administered varying Castor oil doses of low $(12.4 \mathrm{ml} / \mathrm{kg})$, medium $(18.6 \mathrm{ml} / \mathrm{kg})$ and high $(24.8 \mathrm{ml} / \mathrm{kg})$, which were compared with misoprostol group as well as a control group. All animals were euthanized on gestational day 15 and day 20 respectively for the two phases and blood samples collected via cardiac puncture from the apex of the heart for hormonal assay, electrolyte and kidney function tests. The uterus was also removed for histological processing.
Results: The abortifacient effect of castor oil is dose dependent with high dose castor oil group seen to have significantly reduced serum progesterone level ( $32.8 \pm 4.25$ and $40.8 \pm 0.70$ compared with $51.0 \pm 2.00$ of controls), resulted in weight loss and interference with kidney function (increase in serum potassium while decrease in sodium electrolytes). Castor oil also exhibited labor inducing properties.

Conclusion: Castor oil has the potential to induce abortion. This study has demonstrated a possible usage of castor oil in medical induction of labor in rats as it exerted uterotonic principle on the uterus.

Keywords: Castor oil, Misoprostol, Pregnancy, Labour.

\section{Corresponding Author:}

Name: Kadiri R. Eniola

Address: Department of Anatomy, College of Health Sciences

University of Ilorin, Ilorin, Nigeria

Email: kadirire@unilorin.edu.ng

Contact: 08023550366

\section{INTRODUCTION}

Abortion is the termination of pregnancy prior to viability. Induced abortion has been documented in history (1). An estimated figure of twenty-two million unsafe abortions occur yearly worldwide, majority of which occur in developing countries like Nigeria. In earlier times, abortions were unsafe and exerted a heavy toll on women's lives (1). Medical practice has advanced generally, which has led to the development of safer and effective technologies and skills in performing particularly induced abortion. Hence, eliminating unsafe abortions and associated complications entirely, through providing universal access to these services (2).

Induction of labor is the artificial stimulation of uterine contractions before the spontaneous onset of labor, with the aim of achieving vaginal delivery by medical or surgical means. Although many agents are used for labor induction, both the mechanical and pharmacological (use of prostaglandins and oxytocin) methods are still the commonest of the methods (3). There has been report of natural plant extracts such as unripe Carica papaya and Sida alnifolia being able to elicit uterine contraction leading to abortion or induction of labour $(4,5)$.

Misoprostol is a synthetic prostangladin E1 analogue which can be administered orally, vaginally sublingually, bucally and vaginally. It was initially developed for the management of peptic ulcer due to its antisecrotory gastric acid function as well as mucosal protective features (6). These uterotonic and cervical priming properties makes misoprostol to be of high relevance in obstetrics

Cite this article as: Kadir E.R., Ibrahim A., Imam A., Onigbolabi O. G., Imam A. A., Ajao M.S. Castor oil induces morphological changes in endometrium and bio chemical parameters in pregnant Wistar rats. Nig. J. Basic \& Applied Med. Sci. 2021;1(1);1-6.

and gynecology practice. Its clinical application includes medical abortion, medical evacuation for miscarriages, cervical priming before surgical procedures, induction of labour and management of post-partum hemorrhage (6).

Castor oil is an extract from the seed of Ricus communis L. plant. It has different parts, which are of importance and are used for the treatment of several diseases. The preliminary phytochemical screening of $R$. communis revealed the presence of steroids, saponins, alkaloids, flavonoids, and glycosides (7). The major constituent of castor oil which is suspected to have an abortifacient property is the protein ricin, and has also been associated with laxative effects. Castor beans, which is the source of castor oil, contains ricin and some allergenic (2S albumin) proteins (8). The castor seeds endosperm produce ricin, which is classed as a type 2 ribosome-inactivating protein $(9,10)$. Type 2 ribosome-inactivating proteins (ricin from castor oil) are lectins, which and they irreversibly inactivate ribosomes, thereby stopping protein synthesis which culminates to death of cells (8). Castor oil is readily available in markets across Nigeria and Africa generally, and has been reported to have labour inducing properties, hence some pregnant women ingest it to offset labour. Misoprostol is a drug that is associated with multiple complications such as vaginal bleeding, uterine rupture and even maternal death, if not used appropriately. Safety of castor oil, being a plant that's regularly ingested may be explored if its efficacy is similar to that of the prostaglandin in-use. This study therefore sought to investigate the labour and abortifacient properties of castor oil, as well as possible side effects that may Occur.

Pregnancy is a state of high progesterone level. Low levels of progesterone are associated with loss of pregnancy and miscarriages. 
Similarly, a significant drop in serum human chorionic gonadotropin levels (hCG) level is expected following miscarriage or birth. Therefore, these hormones were assayed to observe for their trend in relation to Castor oil exposure.

\section{MATERIALS AND METHODS}

\section{Methodology}

Ethical approval was obtained from the University of Ilroin ethical review committee, with an approval number UERC/ASN /2020/1994.

\section{Animals}

Sixty females and 30 male rats were procured from a standard animal breeder at Ogbomoso, Oyo State. The female Wistar rats, which were 10week old, were housed in wooden cages with 4 females (weighing 155 185g for Phase 1 and 145 175g for Phase II) and 2 males (weighing 205 235g) in each cage. Hand breeding method was used to introduce the female rats to the males. The rats were allowed to be together for 14 hours -6pm to $8 \mathrm{am}$ (Broadman, 2004). Pregnancy was confirmed by the presence of a vaginal mucus plug and sperm positive smear (11). The rats were kept in wire gauzed cages, whose beddings were made of large wood shavings, located in the Animal House of College of Health Sciences, University of Ilorin They were fed properly under a natural light and dark rhythm at room temperature with proper ventilation. The day on which the sperm positive vagina smear was detected was taken as gestational day 1 (12). On the 10th day of pregnancy, the rats were tested to confirm pregnancy by obtaining $0.51 \mathrm{ml}$ of blood from the tail of the rats using a vacuum bottle and a $22 \mathrm{G}$ needle tip, which was then analyzed for the presence of hCG using hCG ELISA test kit (13). A total of 55 pregnant Wistar rats were used for the experiment. The pregnant animals were then randomly divided into 6 groups of 5 animals each in phase I and 5 groups of 5 animals each in the Phase II.

\section{Chemicals}

$200 \mathrm{ug}$ of Misoprostol was diluted with $2 \mathrm{ml}$ of distilled water to give a solution of $100 \mathrm{ug}$ per $\mathrm{ml}$ of distilled water. Castol oil was procured from a standard pharmaceutical company (Rotamedics) in Ilorin, Nigeria.

\section{Experimental Protocol}

The pregnant rats in phase I were randomly distributed into 6 groups (A-F) of 5 rats each and administration was done via oral gavage for three consecutive days, starting from gestational day 12 . Animals in phase II of this study were divided into 5 groups of 5 animals each with administration also lasting for 3 days starting from gestational day 17 .

$\begin{array}{ll}\begin{array}{l}\text { Phase I } \\ \text { A }\end{array} & 2 \mathrm{ml} \text { of distilled water as control group } \\ \text { B } & 100 \mathrm{ug} / \mathrm{kg} \text { of misoprostol } \\ \text { C } & 12.4 \mathrm{ml} / \mathrm{kg} \text { of castor oil } \\ \text { D } & 18.6 \mathrm{ml} / \mathrm{kg} \text { of castor oil } \\ \text { E } & 24.8 \mathrm{ml} / \mathrm{kg} \text { of castor oil } \\ \text { F } & 12.4 \mathrm{ml} / \mathrm{kg} \text { of castor oil }+100 \mathrm{ug} / \mathrm{kg} \text { of misopro }\end{array}$

Nigerian Journal of Basic and Applied Medical Sciences, Vol. 1, No. 1, Sep - Dec, 2021

\author{
Phase II \\ A $2 \mathrm{ml}$ of distilled water as control group \\ B $\quad 100 \mathrm{ug} / \mathrm{kg}$ of misoprostol \\ C $\quad 12.4 \mathrm{ml} / \mathrm{kg}$ of castor oil \\ D $\quad 18.6 \mathrm{ml} / \mathrm{kg}$ of castor oil \\ E $\quad 12.4 \mathrm{ml} / \mathrm{kg}$ of castor oil $+100 \mathrm{ug} / \mathrm{kg}$ of misoprosto
}

At the end of the treatments, all animals were anaesthetized using $20 \mathrm{mg} / \mathrm{kg}$ of ketamine intramuscularly on gestational day 15 for the phase I study and gestational day 20 for the phase II study. The rats were dissected and observations were done for the presence of foetus within the uterus. Absence of foetus in the uterus indicated occurrence of abortion (13), in addition to presence of blood smeared vulva. Blood was drawn by cardiac puncture into serum separating bottles for hormonal assay and the uterus was removed, placed in plain bottles using $10 \%$ formalin in preparation for histological analysis. The fixed tissue was processed into $3.5 \mathrm{um}$ paraffin sections and stained with Hematoxylin and Eosin, to view the uterine endometrium. The images were obtained using Amscope microscope. A 5.0 mega pixel Amscope camera was used to take the photomicrographs at objective lens $\mathrm{x} 10$.

\section{Hormonal Analysis}

\section{hCG Levels}

Analysis of hCG was in serum, via the use of a solid-phase twosite chemiluminescent immunometric assay, calibrated against WHO 3rd IS 75/537, on an Immulite 2000 XPi system (Siemens Healthcare Diagnostics, Deerfield, IL, USA). This Siemens system detects various forms of hCG such as serum intact hCG, hyperglycosylated hCG, serum nicked hCG, serum nicked hyperglycosylated hCG, serum asialo-hCG, serum hCG free b-subunit and serum nicked hCG b (14). An inter assay coefficient of variation of 8.0, 6.3 and $5.1 \%$ at the concentration of 9.7, 53.1 and 821.5 $\mathrm{IU} / \mathrm{L}$, respectively were used (14). The Immulite 2000 is considered as one of the best assays for total hCG. Of importance is that the obtained hCG level ranges in this paper are assay specific, hence do not correspond with hCG values obtained from other assays.

\section{Progesterone Measurement}

Serum progesterone levels were determined using a microparticle enzyme immunoassay Axsym System, whose sensitivity is $0.2 \mathrm{ng} / \mathrm{ml}$. The coefficients of 9.6 and $3.9 \%$ for intra- and inter-observer variations respectively were used. This assay was used for the duration of the study

\section{Electrolytes Analysis}

Blood samples were collected in lithium heparinised bottles, then taken to the laboratory. These were analysed for electrolytes using automated machine Audicom Ac9900 Automatic electrolyte analyser. The results were collated then analysed statistically. 


\section{Statistical Analysis}

All data were expressed as the mean \pm standard error of mean (mean \pm SEM). The differences among the experimental groups were considered statistically significant when $\mathrm{p}$ value is less than 0.05 , using the one-way analysis of variance (ANOVA). Statistical analysis was performed using Graph pad prism version 16

\section{RESULTS}

Physical Observation for Phase I and II In both phases of the study, a noticeable weight loss was recorded in the high dose castor treatment groups, while there was little weight appreciation in the other treatment groups compared to the control. At termination, blood smeared vagina openings were observed especially in the high dose castor oil groups.

\section{Biochemical Analysis for Phase I}

A reduced level of progesterone was observed in administration group $\mathrm{C}$ and $\mathrm{E}$ with significant reduction noticed in the latter. Increase in progesterone level was recorded in group $\mathrm{B}$ and $\mathrm{D}$ but are not significant. A reduced level of hCG was recorded in groups $\mathrm{C}$ and $\mathrm{D}$ but are not of statistical significance. An increase in hCG level was noticed in groups $\mathrm{E}$ and $\mathrm{F}$ but were also not significant when compared to the misoprostol group. An increase in $\mathrm{K}+$ ion concentration was recorded in groups B, D and E. Reduced level was recorded in group $\mathrm{C}$ and no change in level in group $\mathrm{F}$ when compared to the misoprostol group. Decreased level of $\mathrm{Na}+$ concentration was recorded in treatment groups B, C, D and E, decrease is however insignificant. Animal group F showed no increase or decrease when compared to the misoprostol group. A significant increase in the level of urea was recorded in treatment group $\mathrm{C}$ compared to the misoprostol group. Increased urea levels were also noticed in groups $\mathrm{D}$ and $\mathrm{E}$ with no increase or decrease recorded in group $\mathrm{F}$ when compared to the misoprostol group. Increased creatinine levels were recorded in administration group $\mathrm{C}$ and $\mathrm{D}$, decreased level was recorded in group $\mathrm{E}$ and no decrease or increase recorded in group $\mathrm{F}$ when compared to the misoprostol group.
Table 1: Effects of Various Treatments on Body Weight Difference in Phase I

\begin{tabular}{lllll}
\hline Groups & Initial weight $(\mathrm{g})$ & Final weight $(\mathrm{g})$ & Mean diff. $(\mathrm{g})$ & Pvalue \\
\hline A Control & $165 \pm 0.5$ & $179 \pm 1.0$ & $14.5 \pm 1.12$ & $0.000^{* *}$ \\
B Mis $(100 \mathrm{ug} / \mathrm{kg})$ & $185 \pm 9.5$ & $189 \pm 12.5$ & $4.0 \pm 15.7$ & 0.82 \\
$\mathbf{C ~ C a O}(12.4 \mathrm{ml} / \mathrm{kg})$ & $173 \pm 8.08$ & $188 \pm 9.06$ & $15.5 \pm 12.1$ & 0.25 \\
$\mathbf{D ~ C a o}(18.6 \mathrm{ml} / \mathrm{kg})$ & $167 \pm 1.0$ & $179 \pm 3.0$ & $12.0 \pm 3.16$ & 0.06 \\
$\mathbf{E}$ CaO $(24.8 \mathrm{ml} / \mathrm{kg})$ & $151 \pm 1.0$ & $127 \pm 1.50$ & $-24.5 \pm 1.8$ & $0.005^{* *}$ \\
F Mis $+\mathrm{CaO}(\mathbf{1 2 . 4 m l} / \mathrm{kg})$ & $166 \pm 14.0$ & $187 \pm 7.1$ & $20.7 \pm 15.7$ & 0.26 \\
\hline
\end{tabular}

Data represented as mean \pm SEM. $* *(\mathrm{P} \leq 0.01)$; statistically significant difference compared to initial weight.

Table 2: Effects of Various Treatments on Hormones and Electrolytes in Phase I.

\begin{tabular}{|c|c|c|c|c|c|c|}
\hline Groups & $\begin{array}{l}\text { Prog } \\
(\mathrm{ng} / \mathrm{ml})\end{array}$ & $\begin{array}{l}\text { hOG } \\
\text { (iu/ml) }\end{array}$ & $\begin{array}{l}\mathrm{K}^{+} \\
(\mathrm{mEq} / \mathrm{L})\end{array}$ & $\mathrm{Na}^{+}(\mathrm{mEq} / \mathrm{L})$ & Urea $(\mathrm{mmol} / \mathrm{L})$ & $\begin{array}{l}\text { Creatinine } \\
(\mu \mathrm{mol} / \mathrm{L})\end{array}$ \\
\hline A Control & $51.0 \pm 200$ & $280 \pm 0.40$ & $5.75 \pm 0.65$ & $164 \pm 6.50$ & $9.40 \pm 0.60$ & $0.85 \pm 0.25$ \\
\hline B Mis $(100 \mu \mathrm{g} / \mathrm{kg})$ & $53.8 \pm 1.25$ & $3.00 \pm 0.00$ & $7.55 \pm 1.95$ & $135 \pm 3.00$ & $8.75 \pm 0.25$ & $0.70 \pm 0.40$ \\
\hline $\mathrm{C} \mathrm{CaO}(12.4 \mathrm{ml} / \mathrm{kg})$ & $45.9 \pm 248$ & $285 \pm 0.22$ & $5.48 \pm 0.23$ & $138 \pm 6.34$ & $9.20 \pm 0.08$ & $0.80 \pm 0.20$ \\
\hline D CaO $(18.6 \mathrm{ml} / \mathrm{kg})$ & $53.8 \pm 1.25$ & $3.00 \pm 0.00$ & $7.55 \pm 1.95$ & $135 \pm 3.00$ & $8.75 \pm 0.25$ & $0.70 \pm 0.40$ \\
\hline $\mathrm{E} \mathrm{CaO}(24.8 \mathrm{ml} / \mathrm{kg})$ & $32.8 \pm 4.25^{*}$ & $*+4.50 \pm 1.30$ & $9.10 \pm 2.20$ & $123 \pm 3.00$ & $10.15 \pm 1.15$ & $0.45 \pm 0.15$ \\
\hline $\begin{array}{l}\text { F Mis + } \mathrm{CaO} \\
(12.4 \mathrm{~m} / \mathrm{kg})\end{array}$ & $47.4 \pm 1.96$ & $3.47 \pm 1.07$ & $5.80 \pm 0.15$ & $142 \pm 7.51$ & $8.70 \pm 0.10$ & $0.60 \pm 0.17$ \\
\hline
\end{tabular}

Mis misoprostol; $\mathrm{CaO}$ castor oil; * - P $<0.05$ compared to control; + - P $<0.05$ compared to misoprostnol. Statistically significant difference. The levels of progesterone across all the treatment groups.

\section{Histological Evaluation of Endometrium in Phase I}
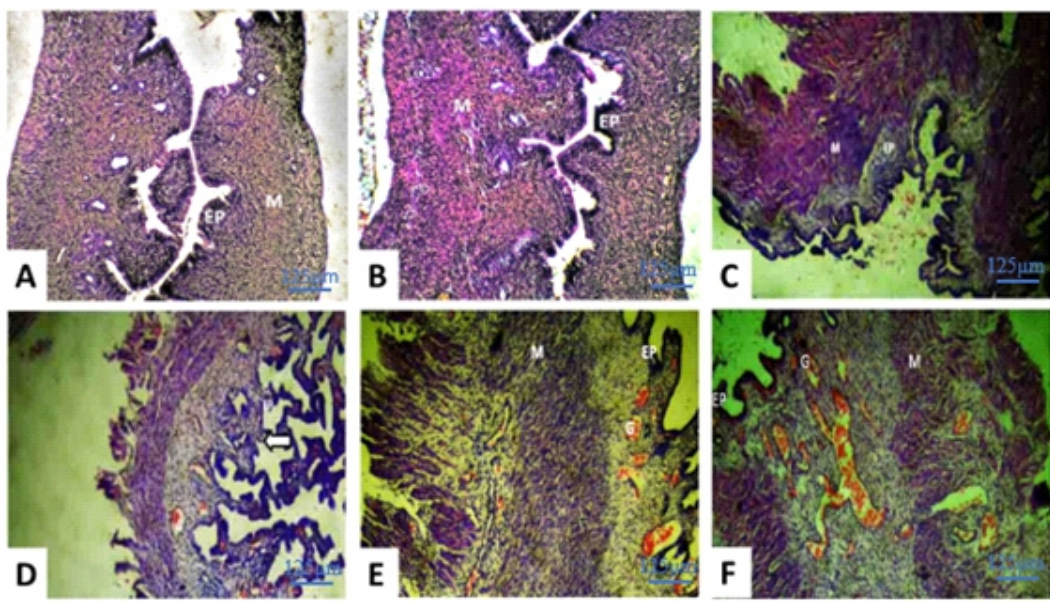

Figure 1: Phase I Photomicrographs showing the histology of the uterus of control (A) showing a normal myometrium and endometrium with various uterine canals(arrow) compared with castor oil and misoprostol treated groups (B-E) which exhibits convoluted epithelial lining, hypertrophied smooth muscle, and increased bleeding. (H\&E X100) *EP- uterine endometrial lining, M- Uterine Myometrium, G- Uterine endometrial Glands

Table 3: Effects of Various Treatments on Body Weight Difference in Phase II

\begin{tabular}{|c|c|c|c|c|}
\hline GROUPS & INTIAL WEIGHT & FINAL WEIGHT & MEANDIFF. & PVALUE \\
\hline AControl & $165 \pm 0.50$ & $233 \pm 7.50$ & $68.0 \pm 7.51$ & $0.01^{*}$ \\
\hline B Mis (100ug/kg ) & $144 \pm 8.0$ & $170 \pm 8.0$ & $26.0 \pm 11.3$ & 0.15 \\
\hline $\mathrm{CCaO}(12.4 \mathrm{ml} / \mathrm{kg})$ & $177 \pm 10.3$ & $2018 \pm 6.17$ & $31.0 \pm 120$ & 0.07 \\
\hline DGaO (18.6m/ $/ \mathrm{kg})$ & $155 \pm 1.76$ & $189 \pm 18.4$ & $33.3 \pm 18.5$ & 0.15 \\
\hline $\begin{array}{r}\mathrm{EMis}+\mathrm{CaO} \\
(124 \mathrm{~m} / \mathrm{kg})\end{array}$ & $145 \pm 9.0$ & $216 \pm 16.0$ & $71.0 \pm 18.4$ & 0.06 \\
\hline
\end{tabular}

Data represented as mean \pm SEM. $*(\mathrm{P} \leq 0.05)$; statistically significant difference compared to initial weight

\section{Biochemical Analysis for Phase II}

A reduced level of progesterone was recorded in group $\mathrm{C}$ and significant reduction recorded in groups $\mathrm{D}$ and $\mathrm{E}$ when compared to the misoprostol group. An increased level 
of hCG was observed in animal groups B and C. A significant decreased level of hCG was noticed in group $\mathrm{D}$, no change in hormone level in group $\mathrm{E}$ was recorded when compared to the misoprostol group. A significantly increased level of $\mathrm{K}+$ concentration was recorded in animal group C. Decreased level of potassium was noticed in group D and significance recorded in group E when compared to the misoprostol group. An increased level of $\mathrm{Na}+$ concentration was recorded in the treatment groups C, D and $\mathrm{E}$ when compared to groups $\mathrm{A}$ and $\mathrm{B}$. significant increase in concentration was however recorded in treatment group E. An increase in urea level was recorded in groups $\mathrm{C}$ and D while a decrease was recorded in group E when compared to the misoprostol group. An increase in creatinine level was observed in treatment groups C and D with a significant increase in treatment group E.

\section{DISCUSSION}

Exposure to misoprostol and castor oil have both proven to have abortifacient effects. The Phase I study showed that exposure to castor oil was associated with significant weight decrease when compared to control and misoprostol groups $(\mathrm{P}<0.005)$. There was similarly significant decrease in serum progesterone level as well as disturbances in the serum electrolytes, especially potassium, sodium and urea, when compared to misoprostol and control groups. There were marked distortions in the endometrial linings and canals in castor oil exposed compared with controls and misoprostol, which were characterized by well preserved histological features. The Phase II study had also similar results, with its moderate dose (group D) showing similar results to the Phase I high dose (group E), as this is a more advanced pregnancy.

Misoprostol is a standard pharmacological drug used for medical induction of abortion and management of miscarriages. The route of administration of castor oil and misoprostol was in accordance with the route of possible human exposure during pregnancy. This study has investigated the comparative effect of misoprostol and castor oil on pregnancy termination.

\section{Phase I}

We investigated the comparative effect of misoprostol and castor oil on abortion. Insignificant increase in body weight was recorded in treatment groups except for the high dose castor oil group where a significant decrease in body weight was recorded. This is likely due to the abortifacient effect of castor oil that resulted to embryonic resorption. Also, this may be explained by the effects of ricinoleic acid in its content, which induces a strong laxative effect. This effect is in congruent with the work of $(4,5,15)$.
Table 4: Effects of Various Treatments on Hormones and Electrolytes in Phase II.

\begin{tabular}{|c|c|c|c|c|c|c|}
\hline Groups & Prog(ng/ml) & $\mathrm{hOG}(\mathrm{iu} / \mathrm{m})$ & $\mathrm{K}^{+}(\mathrm{mEq} / \mathrm{L})$ & $\mathrm{Na}^{+}(\mathrm{mEq} / \mathrm{L})$ & Urea $(\mathrm{mml} / \mathrm{L})$ & Greatinine $(\mu \mathrm{mol} / \mathrm{L})$ \\
\hline AControl & $51.0 \pm 200$ & $280 \pm 0.40$ & $575 \pm 0.65$ & $164 \pm 6.50$ & $9.40 \pm 0.60$ & $0.85 \pm 0.25$ \\
\hline BMs $(100 \quad \mu \mathrm{g} / \mathrm{kg})$ & $54.5 \pm 0.50$ & $3.10 \pm 0.10$ & $890 \pm 0.20$ & $120+1.50$ & $9.70 \pm 0.50$ & $0.30 \pm 0.30$ \\
\hline $\mathrm{CGaO}(124 \mathrm{~m} / \mathrm{kg})$ & $457+3.35$ & $4.00 \pm 1.00$ & $570 \pm 0.44+$ & $158 \pm 187$ & $9.73 \pm 0.13$ & $1.13 \pm 0.49$ \\
\hline $\mathrm{DCaO}(18.6 \mathrm{~m} / \mathrm{kg})$ & $48.5+0.29$ & $+3.00+0.00$ & $7.13+0.75$ & $126+3.84$ & $9.80 \pm 0.42$ & $0.50 \pm 0.20$ \\
\hline $\begin{array}{l}\text { EMis }+\mathrm{CaO} \\
(124 \mathrm{~m} / \mathrm{kg})\end{array}$ & $40.8 \pm 0.70$ & $3.10 \pm 0.10$ & $5.35 \pm 0.05+$ & $138+0.50$ & $9.20 \pm 0.20$ & $250 \pm 0.10+$ \\
\hline
\end{tabular}

\section{Histological Evaluation of endometrium in Phase II}

Figure 2: Phase II Photomicrographs showing the histology of the uterus of control (A) vascularised uterine canals in the endometrium, detached epithelial linning, reduced lamina propria and (E) exhibiting a preserved laminal propria (H\&E X100). EP - uterine endometrial Myometrium

Progesterone is a pro-pregnancy hormone required at high levels throughout the period of pregnancy with levels rising steadily until parturition. Progesterone has been used successfully in preventing spontaneous miscarriage (16). We investigated the effect of misoprostol and castor oil on serum progesterone level and found a reduced level of serum progesterone in castor oil treated groups, which was significant in the high dose group. However, this decrease progesterone level was not seen with the misoprostol group. Our result contradicts the submission of (17) in their work where they reported a steady decrease in the level of serum progesterone after 24 hours of misoprostol administration (17). Significantly reduced serum progesterone level is capable of inducing abortion as it is an essential hormone in the process of reproduction. This was similarly stated by (17) where they documented that decreased progesterone level is a pointer to abortifacient property. It is involved in the menstrual cyclicity, implantation of the zygote as well as maintenance of pregnancy (16). Furthermore, a significantly reduced level of serum progesterone recorded in high dose castor oil group is an indication of some abortifacient property of high dose castor oil. This is similar to the work of (17) on misoprostol (a standard medical abortifacient).

We also determined serum level of human chorionic gonadotropin (hCG), a hormone that's secreted from the placenta, which usually signifies the presence of pregnancy as determined in this study. the result showed decreased hCG level in groups treated with castor oil. This is also consistent with the works of (17). An increase recorded in groups $\mathrm{E}$ and $\mathrm{F}$ contradicts the submission of (17) but does not 
negate the possibility of inducing abortion (18). Posited that abnormal levels of hCG is associated with adverse pregnancy outcomes such as fetal loss, preeclampsia, preterm delivery and fetal growth restriction.

Pregnancy involves remarkable orchestration of physiologic changes. The kidneys are important in the resulting hormonal milieu of pregnancy, by responding and contributing to changes in the pregnant woman and fetus environments (19). The level of serum sodium ion $(\mathrm{Na}+)$ and potassium ion $(\mathrm{K}+)$ were determined to assess relative kidney function. An increase in $\mathrm{K}+$ ion level was recorded in the misoprostol and high dose castor oil groups, which is consistent with (19) where they posited that an increase in body potassium level is as a result of anti-kaliuretic effects of progesterone. Also, the level of $\mathrm{Na}+$ ion measured contradict the conclusion of (19) where they reported a net gain and increase in $\mathrm{Na}+$ in renal physiology during pregnancy. This can be explained by our result which showed decrease $\mathrm{Na}$ ion, with no significant appreciation in weight gain as compared to the control.

The demands of pregnancy on the kidneys are remarkable, which makes it critical for the nephrologist to understand the normal kidney adaptations to pregnancy. There is a rise of $40 \%$ to $50 \%$ in the glomerular filtration rate compared to that of pre-pregnancy levels, which results in lower levels of creatinine, urea, and uric acid (19). A rise in serum urea may be as a result of dehydration from increase fluid loss due to the castor oil effect. Although creatinine levels from our result recorded increased levels in low and medium dose castor oil groups and a decreased level in high dose castor oil group, this is likely due to the interference of the normal pregnancy renal physiology by the castor oil.

During pregnancy, certain physiologic changes occur in the uterus such as hypertrophy and hyperplasia. These occur under the influence of estrogen and progesterone in the early weeks of pregnancy (4). From the results, we recorded hypertrophied smooth muscle and queried bleeding in the treatments groups B-E, which is consistent with the earlier reported work of (4) where they concluded that hypertrophy of the superficial epithelia may be an indication of termination of pregnancy during the later term.

\section{Phase II}

Labour is a process through which the fetus moves from the intrauterine to the extra uterine environment. It is defined clinically as the onset and perpetuation of uterine contractions, which should result in progressive effacement and dilation of the cervix (20). In the second phase of this study, the comparative effect of castor oil and misoprostol on labour induction was studied. An increase in body weight was observed in all administration groups. Though our result contradicts the work of (21) where they recorded a decrease in maternal BMI after treatment with castor oil to induce labour, this may be due to the advanced stage of pregnancy and duration/dose of castor oil administered.

Furthermore, the result of our study recorded a significant decrease in serum progesterone level in the high dose castor oil and the castor oil + misoprostol group. The result of this study is in congruent with the work of (22) where they reported that a dinoprostoneinduced labour was associated with reduced maternal progesterone levels from induction to birth.

Human chorionic gonadotrophin receptors in human myometrium are down-regulated following the onset of labour in both term and preterm deliveries suggesting that hCG may have a role in maintaining uterine quiescence during pregnancy (23). The result of this study showed insignificant increase in misoprostol and low dose castor oil groups. A significant decrease in hCG level was seen in the treatment group administered with high dose castor oil, which is a pointer to a possible non-tocolytic property of castor oil. This observation is supported with the report of (24) where they demonstrated that significantly increased hCG level exerts a significant concentration-dependant relaxant effect on human myometrial tissue obtained rate in pregnancy, raising the possibility of hCG to be used as a tocolytic.

In this study, the effect of the treatment on each animal group on electrolyte levels was determined. Decrease in the level of $\mathrm{K}+$ was noticed in high dose castor oil group and significantly in the combined treatment group. The significant decrease might be as a result of corresponding decrease in the level of progesterone. Our result is supported by the work of (19) where they reported that increase in body progesterone level will yield an increase in body $\mathrm{K}+$ level, this likely due to anti-kaliuretic effect of progesterone.

The result of this study showed a net increase in $\mathrm{Na}+$ ion in all treatment group. In addition, it is hypothesized that the drop in serum sodium is related to the occurrence of vasodilation, arterial underfilling, and subsequent ADH release (25). However, (19) stated in their work that deoxycorticosterone promotes sodium retention and upregulation of sodium pumps across various membranes. These forces are balanced by the natriuretic forces of an increased glomerular filtration rate and increases in atrial natriuretic peptide and progesterone levels, hence leading to net gain in sodium ions, which is in congruent with the result of this study.

Also, increased urea and creatinine levels were recorded in the medium and high dose castor oil treatment groups, this is likely due to decreased water retention and decreased glomerular filtration rate. The result of our study is not in concord of earlier reported work of (19) were they posited that an increase in glomerular filtration rate will lead to a decrease in creatinine, urea and uric acid levels during pregnancy.

During pregnancy, physiological and anatomical changes that occur in the uterus which are likely as a result of secreted hormones to enable the endometrium better adapt to the implantation of uterus. In this study, large well vascularized and hypertrophied uterine canal in endometrium with detached epithelia lining and reduced lamina propria were all noticed in the misoprostol and castor oil group, which can be attributed to the uterotonic principle (which can evoke sustained uterine contraction) that has been exerted on the uterus by misoprostol and castor oil. Similarly, this was also noticed by (4) 
in their work where they studied the effect of unripe pawpaw on the uterus.

\section{Conclusion}

The abortifacient and labour inducing properties of castor oil has been compared with misoprostol. Castor oil when ingested in high dose is associated with distortions in electrolytes and marked weight loss. Therefore, the use of castor oil requires further evaluation in order to ascertain its safety profile as well as its dosage as a labour induction and abortifacient agent. Hence, caution should be exercised by those desiring pregnancy to not ingest castor oil due to its pregnancy termination properties as well as its unconfirmed safety profile and recommended dosages.

\section{ACKNOWLEDGEMENTS}

We will like to appreciate the Anatomy laboratory staff and the College Animal house staff of College of Health Sciences, University of Ilorin, Ilorin, Nigeria.

\section{CONFLICT OF INTEREST}

There is no conflict of interest associated with this work. The study was self-sponsored by all the authors having to contribute financially.

\section{REFERENCES}

1. World Health Organization. Safe abortion: technical and policy guidance for health systems. 2012;64. Available online at https://apps.who.int/iris/bitstream/ handle/10665/70914/9789241548434_eng.pdf;jsessionid=31E0F7DBF2AD8F 39BE11A13E9BCDEF9C?sequence=1 Accessed on 20/05/2021

2. World Health Organization. Unsafe abortion incidence and mortality Global and regional levels in 2008 and trends during 1990 - 2008. Inf Sheet. 2008;18. Available online at https://apps.who.int/iris/bitstream/handle/10665/75173/ WHO_RHR_12.01_eng.pdf?sequence=1 Accessed on 13/02/2021

3. Kavita G, Jaya K.G, Disha A.R. MVB. Induction of Labor : A Review. Indian J Clin Pr. 2014;24(11):105764.

4. Sumanth M, Ugendra K. Research Article: Effect of unripe carica papaya on uterus. Int J Res Ayurveda Pharm. 2013;4(3):3458.

5. Akah PA. (1994). Abortifacient Activity of some Nigerian Medicinal Plants. Phythotherapy research, 1994;8:1068.

6. Tang OS, Gemzell-danielsson K, Ho PC. Misoprostol : Pharmacokinetic profiles, effects on the uterus and side-effects. Int J Gynaecol Obs, 2007;99:1607.

7. Ahmed M. Peptic Ulcer Disease. Intech, 7:32 137-144.

8. Patel VR, Dumancas GG, Viswanath LCK, Maples R, Subong BJJ. Castor Oil : Properties, Uses, and Optimization of Processing Parameters in Commercial Production. Lipids insight. 2016;9: 62-74.

9. Stirpe F, Battelli MG. (2006). Ribosome-inactivating proteins : progress and problems. Cellular and molecular life sciences. 2006;63:18501866.

10. Fernandes K, Godoy M. Simultaneous allergen inactivation and detoxification of castor bean cake by Simultaneous allergen inactivation and detoxification of castor bean cake by treatment with calcium compounds. Braz J Med Biol Res. 2012;45(11): 1002-1010.

11. Extended one-generation reproductive toxicity test guideline. OECD guideline for the testing of chemicals. Version 4. 2008. Available online at https://www.oecd.org/chemicalsafety/testing/40899803.pdf Accessed 04/01/2021
12. Kennedy GL, Lu M, Mcalackt JW. (1987).Teratogenic Evaluation Of 1, 1, 3 , 3- Tetrabutylurea In The Rat Following Dermal Exposure. Food and chemical toxicology. 1987;25(2):1736.

13. Namulindwa A, Nkwangu D, Oloro J. (2015). Determination of the abort ifacient activity of the aqueous extract of Phytolacca dodecandra ( L ' Her) leaf in Wistar rats. African Journal of Pharmacy and Pharmacology. 2015;9 (3):437.

14. Salami SA, Raji Y. (2015). Generational reproductive outcomes in Wistar rats maternally exposed to Ricinus communis oil at different stages of gestation. Journal of Developmental Origins of Health and Disease. 2015;6:44353.

15. Tunaru S, Althoff TF, Nüsing RM, Diener M, Offermanns S. (2012). Castor oil induces laxation and uterus contraction via ricinoleic acid activating prostaglandin EP 3 receptors. Pnas, 2012;2:16.

16. Carlo G, Renzo D, Giardina I, Clerici G, Mattei A, Alajmi AH, et al. (2012). The role of progesterone in maternal and fetal medicine. Gynecological Endocrinology. 2012; 28(11): 925932.

17. Honkanen H, Ranta S, Ylikorkala O, Heikinheimo O. (2002). The kinetics of serum hCG and progesterone in response to oral and vaginal administration of misoprostol during medical termination of early pregnancy. Human Reproduction. 2002;17(9):23159.

18. Olsen RN, Woelkers D, Lacoursiere DY. SMFM Papers Abnormal secondtrimester serum analytes are more predictive of preterm preeclampsia. Am J Obs Gynecol. 2012;207(3):228.e1-228.e7.

19. Cheung KL, Lafayette RA. Renal Physiology of Pregnancy. Adv Chronic Kidney Dis. 2014;20(3):2091.

20. El-gawad SA. Castor Oil Safety and Effectiveness on Labour Induction and Neonatal Castor Oil Safety and Effectiveness on Labour Induction and Neonatal Outcome. Journal of Biology, Agriculture and Healthcare, 2014;(4) 2224-3208.

21. Azhari S, Pirdadeh S, Lotfalizadeh M, Shakeri MT. Initiating labor in term pregnancy. Saudi medical journal. 2006;98(April):10114.

22. Konopka CK, Morais EN, Naidon D, Pereira AM, Rubin MA. Maternal serum progesterone, estradiol and estriol levels in successful dinoprostone-induced labor. Brazilian Journal of Medical and Biological Research. 2013; 46: 91-97.

23. Zuot J, Lei M. Human Myometrial Hormone Receptors. The Journal of Clinical Endocrinology and Metabolism. 2015; 71(3): 110-234.

24. Slattery MM, Brennan C, Leary MJO, Morrison JJ. Human chorionic gonadotrophin inhibition of pregnant human myometrial contractility. British Journal of Obstetrics and Gynaecology. 2001; 108: 704-708

25. Schrier RW. Systemic Arterial Vasodilation, Vasopressin, and Vasopressinase in Pregnancy. J Am Soc Nephrol. 2010; 21: 570572. 